\title{
Design and Optimization of Critical Parameters of a Muffler for Noise Reduction
}

\author{
R. Praveen kumar ${ }^{1}$, M. Sasikumar ${ }^{1 *}$ and S. Dinesh Kumar ${ }^{2}$ \\ 'School of Mechanical and Building Sciences (SMBS), VIT University, Chennai Campus, Chennai - 600127, Tamil \\ Nadu, India; Praveen.kumar2013@vit.ac.in, sasikumar.m@vit.ac.in \\ 2Department of Automobile Engineering, Karpaga Vinayaga College of Engineering and Technology, \\ Chennai -600024, Tamil Nadu, India; softdin@gmail.com
}

\begin{abstract}
Objective: The main aim of this paper is redesigning Muffler internal layout to improve the attenuation based on the critical parameters. Analyzing the baseline muffler design, the area of improvement is identified as frequency range of $250 \mathrm{~Hz}-800 \mathrm{~Hz}$. Methods: By keeping the volume of muffler constant and varying the critical parameters such as perforation size, length of perforations on the pipe, length of intermediate pipes and the position of baffles thirty iterations were performed. Finding: The exhaust gas flow path was modified in the new concept for better attenuation. Second and fourth chambers were made as expansion chambers. First and third chambers were made as Helmholtz chambers. With this basic flow path, further fine tuning was done by varying the critical parameters. Applications: With this current design and optimistic characteristic, the candidate's muffler design can be used as noise reduction muffler in automobile industries.
\end{abstract}

Keywords: Acoustics, Muffler, Sensitivity Analysis, Transmission Loss

\section{Introduction}

The muffler or silencer is a device used for attenuation of noise emitted by exhaust of an IC Engine ${ }^{1}$. Noise emitted by vehicles is regulated based on PBN test which includes noise from different sources like exhaust, gearbox, engine, tyres, etc. Higher noise causes discomfort in public, passengers and driver. Undoubtedly, lesser noise can make the environment friendlier. To reduce the intensity of sound emitted out of vehicle from exhaust, muffler is a primary means which has to be engineered to attenuate noise meeting required $\mathrm{dB}$ levels and sound quality, emissions based on environment norms.

A muffler may be described as any section of doctor pipe that has been shaped or treated with the intention of reducing the transmission of sound, while at the same time allowing free flow of a gas ${ }^{2-4}$. Mufflers are made up of reactive and resistive elements. Mufflers perform the silencing function by absorption, restriction and reflec- tion methods. Mufflers can use one, a combination or all of these methods to attenuate sound ${ }^{5}$. Mufflers are conventionally classified as dissipative or reactive, depending on whether the acoustic energy is dissipated into or is reflected back by area discontinuities ${ }^{6}$. Noise, Vibration and Harshness performance relate to the vibrational response of the vehicle to driving conditions. As such, stiffness of the vehicle structure, the mass of the vehicle, and the damping effects of the vehicle suspension all come into play ${ }^{?}$.

GT-POWER is the market leading Engine Simulation Software, used by every major Engine manufacturer for the design and development of their Engines. GT-POWER includes a complete After treatment(AT) device library that enables to model any AT device in isolation or within an integrated system, while providing the user the complete flexibility to modify and impose the participating kinetic mechanisms. It is a single tool for simulation of all aspects of Engine and vehicle sys-

${ }^{*}$ Author for correspondence 
tems and it allows modeling of AT systems together with the vehicle, Engine, thermal management, and control systems, making this tool uniquely suitable for collaborative development. GEM3D is a tool that can be used to build 3D models of flow systems that can be discretized and made into model files for use with GT-SUITE. GEM3Dcanbeusedto build any flow system that contains only flow components like pipes, mufflers, manifolds, air boxes, etc.

Figure 1 shows an acoustical model of the baseline muffler created in GT-power for simulation of transmission loss values.

\section{Acoustical filter performance parameters}

A typical Exhaust Muffler or a Low-pass Acoustic Filter with its terminations is shown in Figure 2. Invariably, the muffler has a small diameter pipe on either end. The one upstream is called the exhaust pipe and that downstream is called the tail pipe. The middle, larger diameter portion may be called the muffler proper. In general, for a n-element muffler, the tail pipe would be the first element and the exhaust pipe, the $\mathrm{n}^{\text {th }}$. The performance of an acoustic filter is measured in terms of the parameters, Insertion loss, IL; Transmission loss, TL; and Level difference, LD or Noise reduction, NR.

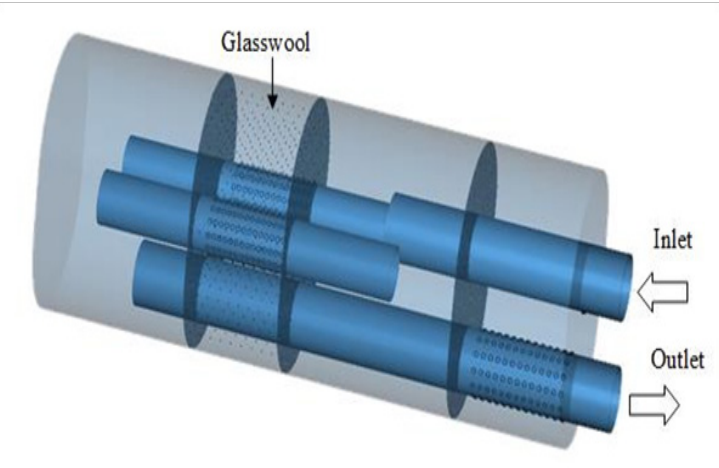

Figure 1. Baseline Design.

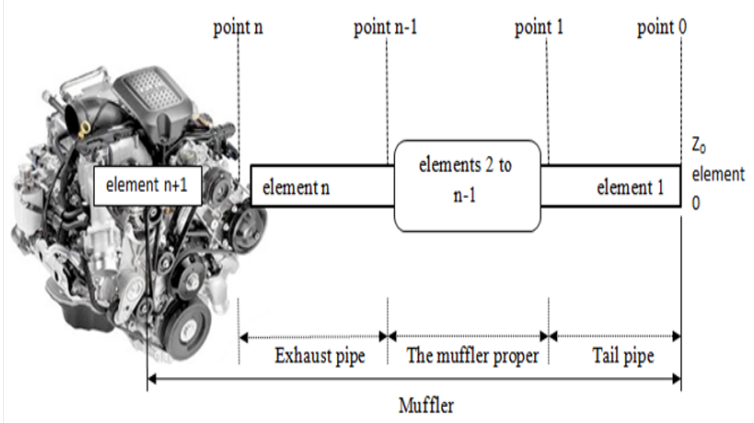

Figure 2. Typical engine exhaust system.

\section{Experiments and Methods}

The baseline muffler design consists of four chambers, two expansion chambers and two Helmholtz chambers ${ }^{8}$. An absorption chamber with glass wool is used to attenuate high frequency noise. An acoustical model of the baseline muffler was created in GT-power Figure1: and simulated for transmission loss values. Figure 3 shows the transmission loss curve for the baseline muffler.

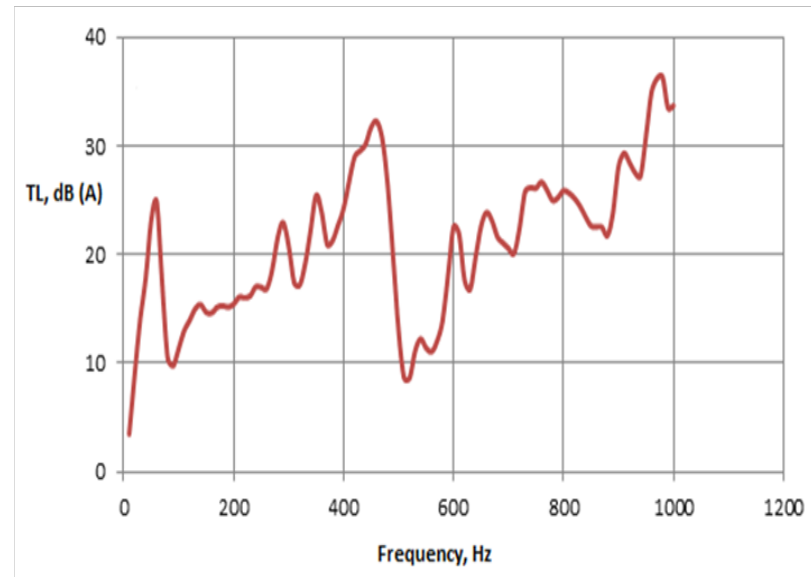

Figure 3. TL curve of the baseline muffler.

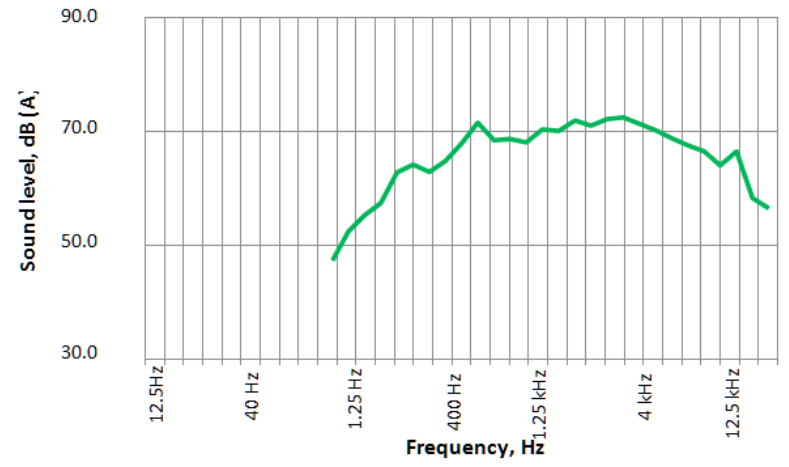

Figure 4. PBN spectrum of the baseline muffler- driver side.

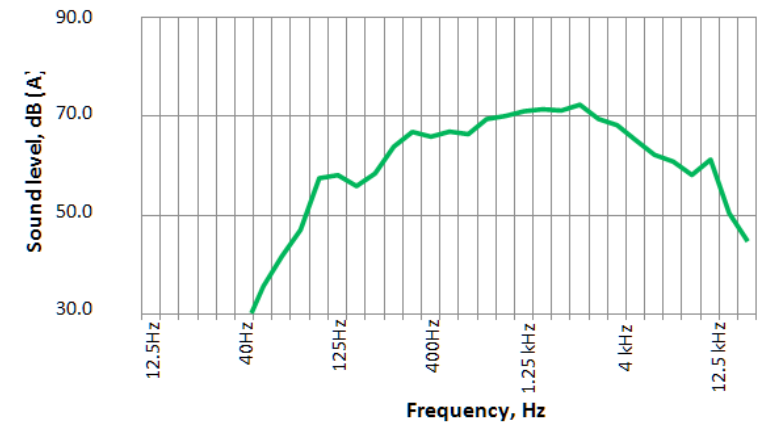

Figure 5. PBN spectrum of the baseline muffler- codriver side. 
PBN SPECTRUM: PBN trials were carried out on a $180 \mathrm{hp}$ vehicle. The PBN spectrum indicates that, improvement is needed in the frequency range of $250 \mathrm{~Hz}-800 \mathrm{~Hz}$ as shown in Figure 4.

$\mathrm{PBN}$ trial includes both driver side and co-driver spectrum values. The PBN

spectrum of the baseline muffler with co-driver side can be seen in Figure 5.

\section{Result and Discussion}

\subsection{Sensitivity Analysis}

\subsubsection{Effect Of Perforations (Hole Diameter)}

Perforation size, perforation length and open area ratio (ratio of the total area of perforations to the cross sectional area of the pipe) play a major role in designing the Helmholtz chamber-11. One of the critical factors is perforation size. Different perforation size for different case consider in this work is shown in Table 1. Open area ratio1.1is maintained constant in all the models.

Three different perforation sizes $3 \mathrm{~mm}, 4 \mathrm{~mm}$ and $5 \mathrm{~mm}$ are cornered. Out of three combinations, perforations of $5 \mathrm{~mm}$ in both inlet and outlet pipes are finalized based on Transmission Loss comparisons. By maintaining the same open area ratio, three different perforation sizes were simulated and the performance of $5 \mathrm{~mm}$ perforation diameter gave better attenuation as shown in the Figure 6 .

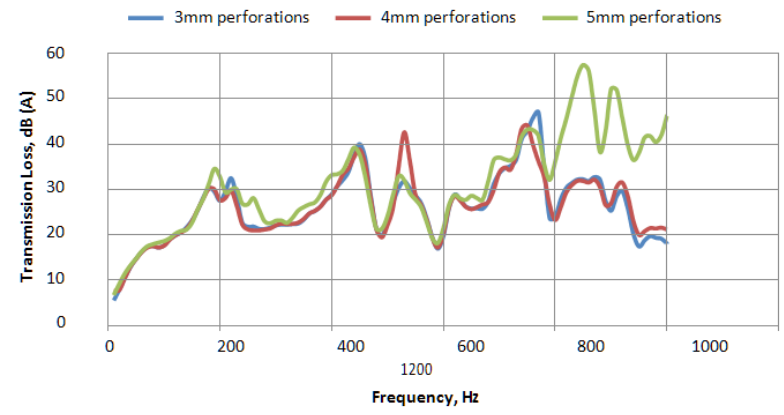

Figure 6. Effect of perforation diameter on performance.

Table 1. Diameter of Perforations

\begin{tabular}{|l|l|l|}
\hline CASEI & $\begin{array}{l}\text { Inlet pipe } \\
\text { perforation } 3 \mathrm{~mm}\end{array}$ & $\begin{array}{l}\text { Outlet pipe } \\
\text { perforation } 3 \mathrm{~mm}\end{array}$ \\
\hline CASEII & $\begin{array}{l}\text { Inlet pipe } \\
\text { perforation } 4 \mathrm{~mm}\end{array}$ & $\begin{array}{l}\text { Outlet pipe } \\
\text { perforation } 4 \mathrm{~mm}\end{array}$ \\
\hline CASEIII & $\begin{array}{l}\text { Inlet pipe } \\
\text { perforation } 5 \mathrm{~mm}\end{array}$ & $\begin{array}{l}\text { Outlet pipe } \\
\text { perforation } 5 \mathrm{~mm}\end{array}$ \\
\hline
\end{tabular}

Vol 9 (47) | December 2016 | www.indjst.org

\subsubsection{Effect of Baffle Position}

In Expansion chamber mufflers, larger the expansion ratio the greater the transmission loss ${ }^{12}$. Different baffle position for different case consider in this work is shown in Table 2.

From above three cases, we observe that $5 \mathrm{~mm}$ hole diameter on both inlet and outlet pipes with tuned second expansion chamber ( $215 \mathrm{~mm}$ length) affects transmission loss relatively high when compared to first expansion chamber and second expansion chamber with $195 \mathrm{~mm}$ length. Chamber length of $195 \mathrm{~mm}$ is not considered because of high back pressure. By maintaining the muffler volume same, results were observed by tuning the first expansion chamber and second expansion chamber with different chamber lengths in Figure 7. Second expansion chamber length $215 \mathrm{~mm}$ has a relatively high transmission loss compared to first expansion chamber of length $180 \mathrm{~mm}$.

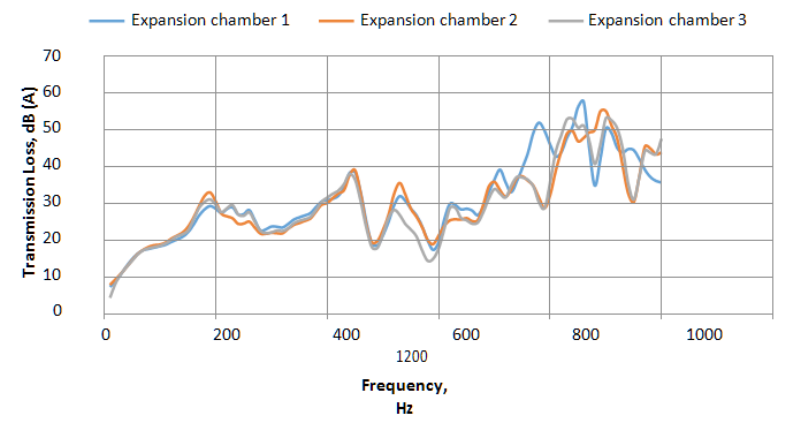

Figure 7. Effect of baffle position on performance.

Table 2. Baffle position

\begin{tabular}{|l|l|l|}
\hline CASEI & $\begin{array}{l}\text { Second chamber } \\
\text { tuning } \\
\text { (first expansion } \\
\text { chamber) }\end{array}$ & $\begin{array}{l}\text { Two Helmholtz } \\
\text { chamber length as } \\
\text { constant }\end{array}$ \\
\hline CASEII & $\begin{array}{l}\text { Fourth chamber } \\
\text { tuning } \\
\text { (second expansion } \\
\text { chamber) }\end{array}$ & $\begin{array}{l}\text { First expansion } \\
\text { chamber and two }\end{array}$ \\
\hline CASEIII & $\begin{array}{l}\text { Second expansion } \\
\text { length as constant }\end{array}$ \\
\hline chamber tuning & $\begin{array}{l}\text { First and second } \\
\text { chambers length as } \\
\text { constant }\end{array}$ \\
\hline
\end{tabular}

\subsubsection{Effect of Intermediate Pipelength}

One of the critical parameters affecting the performance characteristics of the muffler is the length of intermedi- 
ate pipe $\mathrm{i}^{\underline{13}}$. In concept 1 , intermediate pipe length is varied and a simulation was made. Different pipe length for different case consider in this work is shown in Table 3.

It is observed that the tuning of intermediate pipes shows considerable variation in transmission loss values. In the low frequency range, all the models performed same. In the frequency range of $580 \mathrm{~Hz}$ to $840 \mathrm{~Hz}$ intermediate pipe 2 shows a better transmission loss compared to other models. Results are plotted as shown in Figure 8.

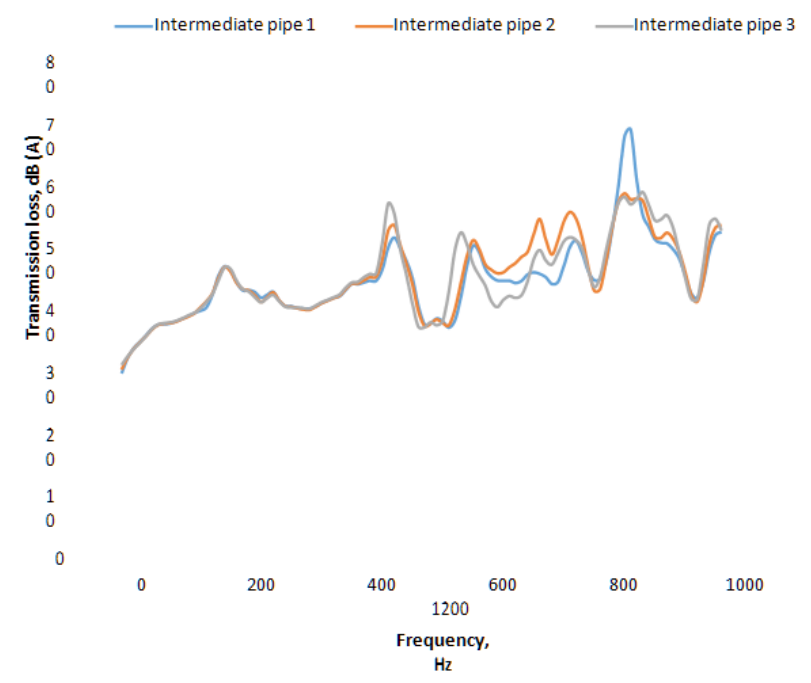

Figure 8. Effect of intermediate pipe length.

Table 3. Intermediate pipe length

\begin{tabular}{|l|l|l|}
\hline $\begin{array}{l}\text { CASEI } \\
\text { (Figure 6.10) }\end{array}$ & $\begin{array}{l}\text { Intermediate pipe length } \\
\text { located in } \\
\text { Helmholtz chamber is } \\
\text { reduced to } 190 \mathrm{~mm}\end{array}$ \\
$\begin{array}{l}\text { CASEII } \\
\text { (Figure6.11) }\end{array}$ & $\begin{array}{l}\text { Diameter of } \\
\text { Intermediate } \\
\text { pipes as } \\
\text { constant }\end{array}$ & $\begin{array}{l}\text { Intermediate pipe length } \\
\text { located in } \\
\text { Helmholtz chamber is } \\
\text { reduced to 250mm }\end{array}$ \\
\cline { 3 - 4 } $\begin{array}{l}\text { CASEIII } \\
\text { (Figure 6.12) }\end{array}$ & & $\begin{array}{l}\text { Intermediate pipe length } \\
\text { located in }\end{array}$ \\
\hline
\end{tabular}

\subsection{Concepts Finalization}

The concepts finalized from the sensitivity analysis are listed in the table 4.
From the analysis done using GT-SUITE software, the overall Transmission Loss graph was plotted by observing the effect of critical parameters which affects the performance characteristics of Exhaust Muffler. In comparison, it is clear that, conceptually with $5 \mathrm{~mm}$ perforation diameter on both inlet and outlet pipes showed better performance when compared to others. The effect of parameters was further made in Concept 2 and the designs which performed better Transmission Loss were selected for experimental testing.

From PBN spectrum, peak is observed at $315 \mathrm{~Hz}$ and need to be reduced with the new muffler design. New Concepts were finalized by keeping in mind that the performance should be improved at the frequencies of $315 \& 500 \mathrm{~Hz}$ and also an improvement in performance at first order $(120 \mathrm{~Hz})$ will be very useful.

The overall Transmission Loss result for the finalized concepts are plotted is shown in Figure 9.

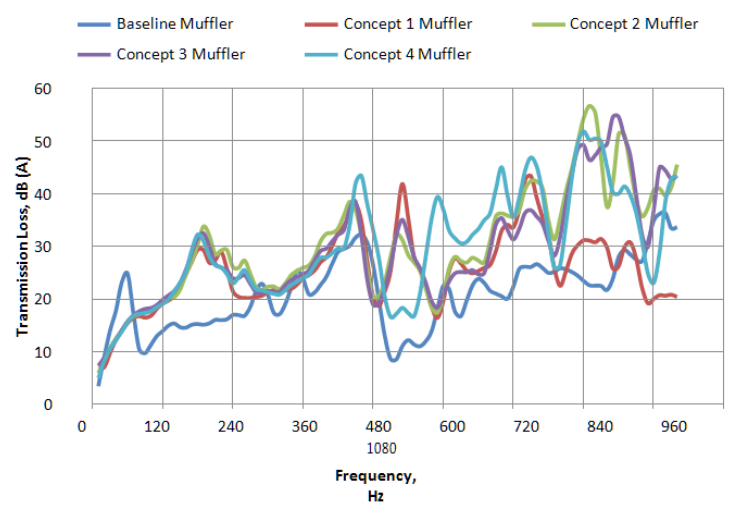

Figure 9. Overall Transmission Loss value.

Table 4. Concept finalization

\begin{tabular}{|l|l|}
\hline CONCEPT 1 & $\begin{array}{l}\text { 4mmperforation diameter on both Inlet } \\
\text { and Outletpipes. }\end{array}$ \\
\hline CONCEPT 2 & $\begin{array}{l}\text { 5mmperforation diameter on both Inlet } \\
\text { and Outletpipes. }\end{array}$ \\
\hline CONCEPT 3 & $\begin{array}{l}\text { 5mm perforation diameter on both } \\
\text { inlet and outlet pipes with tuned second } \\
\text { expansion chamber. }\end{array}$ \\
\hline CONCEPT 4 & $\begin{array}{l}\text { 5mmperforation diameter on both inlet } \\
\text { and outlet pipes with intermediate pipe } \\
\text { length reduction. }\end{array}$ \\
\hline
\end{tabular}

\section{Conclusion}

1. The need for design verification will always be necessary at the end of each step, although the prac- 
tical approach has become an important tool. This approach serves the purpose of reducing the number of iterations, product development time and cost with better design.

2. After verifying the effect of critical parameters, new Mufflers were developed to clear back pressure and PBN targets after transmission loss test in laboratory level. Improvements in the performance of the Mufflers help in reducing the number of noise shields.

3. Mufflers with dedicated chambers for expansion and Helmholtz resonator are better in performance compared to the Mufflers with a combination of the chambers. Higher perforation size helps in attenuating low frequency and vice versa. Longer the chamber length better is the attenuation at low frequency.

4. The finalized concept Mufflers have shown improvement in performance at the frequencies of $315 \& 500$ $\mathrm{Hz}$. In comparison, it is clear that, conceptually with $5 \mathrm{~mm}$ perforation diameter on both inlet and outlet pipes showed better performance when compared to other concepts and the experimental result has been correlated with the analytical result.

\section{Scope of Future Work}

By optimizing all the critical parameters, new mufflers were designed and transmission loss analysis was performed to compare the performance of other concept mufflers. Analyzing the new muffler concepts, concept 2 mufflers shows higher transmission loss and improvement in the frequency range of $250 \mathrm{~Hz}-800 \mathrm{~Hz}$ compares with baseline muffler and other concept mufflers which can reduce the noise peaks at problematic frequencies $315 \mathrm{~Hz}$ and $500 \mathrm{~Hz}$ respectively. Pass-by Noise test for the new developed muffler (concept 2 mufflers)is suggested.

\section{References}

1. Munjal ML. Acoustics of ducts and Mufflers with Applications to Exhaust and Ventilation System Design, $1^{\text {st }}$ (edn). Wiley-Inter science: US. 1987; 1-328.

2. Potente P, Daniel D. General Design Principles for an Automotive Muffler. Proceedings of acoustics Australian Acoustical Society, Western Australia. 2005; 1-6.
3. Sherekar V, Dhamangaonkar PR. Design Principles for an Automotive Muffler. International Journal of Applied Engineering Research. 2014; 9(4):483-89.

4. Rahman M, Sharmin T, Hassan AFE, Al Nur M. Design and Construction of a Muffler for Engine Exhaust Noise Reduction. Proceedings of the International Conference on Mechanical Engineering. Dhaka, Bangladesh. 2005; 11(3):85-91.

5. Vaidya PPV, Hujare H. Optimization of Sound Pressure Level of Air Intake System by using GT-Power. International Journal of Emerging Science and Engineering. 2014; 2(8):9-11.

6. Tao Z, Seybert AF. A Review of Current Techniques for Measuring Muffler Transmission Loss. Society of Automotive Engineers. 2003; 1-5.

7. Kim KS, Choi DS. Study on Vibration Characteristics through Torsion Spring Constants within Automobile Muffler. Indian Journal of Science and Technology. 2015 Jan 1; 8(S1):210-5.

8. Pal S, Golan TS, Kumar V, Jain V, Ramdas N, Sharma OP. Design of a Muffler and Effect of Resonator length for 3 Cylinder SI Engine. IOSR Journal of Mechanical and Civil Engineering (IOSR-JMCE). 2014; 11(3):1-7.

9. Allam S. Numerical Assessment and Shape Optimization of Dissipative Muffler and Its Effecton I.C. Engine Acoustic Performance, American Journal of Vehicle Des. 2014; 2(1):22-31.

10. Pujari NV, Mahajan SR, Mohite YB. Optimization of Silencer- An Integrated Approach of Acoustic Performances and Back pressure. International Journal of Emerging Science and Engineering. 2013; 3(22):1-3.

11. Shah S, Sasisankaranarayana K, Kalyankumar S, Hatti H, Thombare DG. A Practical Approach towards Muffler Design, Development and Prototype Validation, SAE International. 2010; $1-11$.

12. Gopan MB, Annamalai K. Optimizing the Back Pressure of 4 Stroke Engine by using Baffle Plates in Tail Pipe. Indian Journal of Science and Technology. 2015 Nov; 8(31):1-6.

13. Lou H, Tse C, Chen YNC. Modeling and Applications of Partially Perforated Intruding Tube Mufflers. Applied Acoustics. 1995; 44(4):99-116. 